\title{
Os Critérios de Verificação da Representatividade Adequada e a Prática do Modelo Representativo Brasileiro
}

\author{
The Verification Criteria of the Adequate Representativeness and the Practice of the Brazilian \\ Representative Model
}

Vitória de Sousa Pontes ${ }^{1}$

${ }^{1}$ Universidade do Estado do Rio de Janeiro - UERJ, Brasil

\begin{abstract}
Resumo
O Brasil adota um modelo representativo de processo coletivo no qual um legitimado extraordinário, por expressa autorização legal, conduz um processo em nome próprio, na defesa de direitos que pertencem a um agrupamento humano. Nesse contexto, o devido processo legal coletivo tornou-se um referencial teórico para que considerável parte da doutrina passasse a admitir

a possibilidade de controle, no caso concreto, da adequação da representatividade deste legitimado extraordinário. O presente trabalho procura abordar os critérios definidos e utilizados para o referido controle, em especial a pertinência temática, a partir da análise do seu conteúdo e do seu alcance em um modelo representativo que, embora misto, é majoritariamente público na prática. O problema que se apresenta é, portanto, verificar se os critérios são eficientes para a realidade do processo coletivo brasileiro.
\end{abstract}

Palavras-chave: representatividade adequada; controle ope judicis; pertinência temática

\begin{abstract}
Brazil adopts a representative model of collective procedure in which an extraordinary legitimate singular part, thru a formally written legal authorization, conducts the process in his own name, in defense of rights that belong to a group of people. In this context, the collective due process of law has become a theoretical reference for a considerable part of the doctrine to admit the possibility of controlling, in the specific case, the adequacy of the representativeness of this extraordinary legitimate part. The present work seeks to approach the criteria defined and used for that control, especially the thematic pertinence. This is done by analyzing its content and scope in a representative model that, although mixed, is mostly public in practice. The problem lies in verifying if the criteria are, therefore, efficient for the reality of the Brazilian collective process.
\end{abstract}

Keywords: adequate representativeness; ope judicis control; thematic pertinence

\section{Introdução}

Partindo do referencial teórico do devido processo legal coletivo, o presente trabalho se propõe a analisar o controle da representatividade adequada dos legitimados extraordinários em relação à coletividade substituída no caso concreto.

A referida análise, realizada a partir de pesquisa bibliográfica, envolve o estudo tanto dos fundamentos para realização desse controle, quanto dos critérios apontados - pela doutrina e jurisprudência - como necessários para essa finalidade.

Para tanto, faz-se necessária uma introdução a respeito do processo coletivo, a fim de abarcar o contexto em que se insere o controle da legitimação coletiva. O primeiro problema percebido é a 
ausência de previsão legal expressa sobre a necessidade de se aferir, diante das peculiaridades do caso concreto, a adequação da representatividade do legitimado extraordinário.

É demonstrado, então, como considerável parte da doutrina defende que o devido processo legal coletivo não só autoriza, como torna fundamental a realização de um controle sobre a representatividade adequada.

Em seguida, a pesquisa volta-se a analisar um dos parâmetros mais consagrados para a verificação da representatividade adequada: a pertinência temática. $O$ estudo do seu conteúdo é então inserido no contexto do modelo representativo brasileiro, que passa também a ser objeto de análise.

É nesse ponto que se encontra o maior problema que o presente trabalho pretende demonstrar e enfrentar, assim como a relevância do tema: pela pesquisa realizada, constata-se que, em que pesem as ações coletivas sejam propostas, na prática, em maior quantidade por entes públicos, os parâmetros mais consagrados para o controle da representatividade adequada são voltados em maior medida para pessoas jurídicas de direito privado.

A partir disso, a utilização do critério da pertinência temática é especialmente problematizada diante do modelo representativo brasileiro, que, na prática, é eminentemente público.

Ao final, o trabalho foca em traçar um controle de legitimação coletiva com parâmetros mais condizentes com uma verificação de fato à luz do caso concreto da representatividade adequada, retomando, para isso, referenciais do devido processo legal coletivo.

\section{O Processo Coletivo e o Controle da Legitimação Coletiva}

Embora existam alguns anteprojetos de lei para ações coletivas em tramitação, atualmente o Brasil conta com um microssistema de processo coletivo, formado não só pela influência de normas gerais, mas também pela reunião intercomunicante de diversos diplomas legais. ${ }^{1}$

Esse microssistema² é composto, em seu núcleo, pelo Código de Defesa do Consumidor (CDC), pela Lei da Ação Civil Pública e pela Lei da Ação Popular. O mesmo conta ainda com diversas leis avulsas, como a Lei de Improbidade Administrativa e a Lei do Mandado de Segurança. É articulado também, em um diálogo de fontes, com a Constituição da República Federativa do Brasil de 1988 (CRFB/88) e o Código de Processo Civil de 2015 (CPC/15). ${ }^{3}$

Estes diplomas são intercambiantes entre $\mathrm{si}^{4}$ e, como explica Júlio Camargo de Azevedo, encontram em sua intertextualidade sistêmica o pilar que permite a integração dinâmica e flexível desse

$\overline{1}$ AZEVEDO, Júlio Camargo de. O microssistema de processo coletivo brasileiro: uma análise feita à luz das tendências codificadoras. Revista Eletrônica de Direito Processual - REDP, Rio de Janeiro, v. VIII, n. 8, pp. 478-499, 2011, p. 483. Disponível em: <https://www.e-publicacoes.uerj.br/index.php/redp/article/view/20831/15109>. Acesso em: $09 / 09 / 2020$.

2 Esse microssistema foi reconhecido pelo Superior Tribunal de Justiça, em 2004, no voto do Ministro Luiz Fux: “A lei de improbidade administrativa, juntamente com a lei de ação civil pública, da ação popular, do mandado de segurança coletivo, do Código de Defesa do Consumidor e do Estatuto da Criança e do Adolescente e do Idoso, compõem um microssistema de tutela dos interesses transindividuais e sob esse enfoque interdisciplinar interpenetram-se e subsidiam-se (...)" (BRASIL. Superior Tribunal de Justiça (1ํo Turma). Recurso Especial 510.150/MA, Relator: Ministro Luiz Fux, 17 de fevereiro de 2004, p. 11. Disponível em: <https://scon.stj.jus.br/SCON/GetInteiroTeorDoAcordao?num_registro=200300078957\&dt_ publicacao $=29 / 03 / 2004>$. Acesso em: 09/09/2020).

3 DIDIER JR., Fredie; ZANETIJR., Hermes. Curso de Direito Processual Civil: processo coletivo. V. 4, 14. ed. Salvador: Ed. Juspodivm, 2020, p. 77.

$4 \quad$ Ibid, p. 79. 
microssistema. ${ }^{5}$ Ademais, essas leis, para aumentarem sua flexibilidade e durabilidade, ainda encontram no CPC/15 uma regulamentação subsidiária e supletiva. ${ }^{6}$

O processo coletivo, portanto, se desenvolve na forma das disposições que compõem esse microssistema e pode ser definido, segundo Edilson Vitorelli, como a técnica processual colocada à disposição da sociedade, pelo ordenamento, para permitir a tutela jurisdicional dos direitos afetados pelos litígios coletivos. ${ }^{7}$

No Brasil, o modelo de processo coletivo adotado é o representativo. Como explica Edilson Vitorelli, nesse modelo, um sujeito que não titulariza o direito material, ou, pelo menos, não titulariza a totalidade dele, é legitimado pela ordem jurídica para conduzir um processo cuja decisão, ao final, terá efeitos sobre a sociedade titular do direito litigioso. ${ }^{8}$

Assim, em que pese existam alguns entendimentos distintos na doutrina ${ }^{9}$, autores como Fredie Didier Jr. e Hermes Zaneti Jr. entendem ser possível compreender a legitimação ao processo coletivo como extraordinária, na medida em que se autoriza um ente a defender, em juízo, situação jurídica de que é titular um grupo ou uma coletividade, não havendo coincidência entre o legitimado e o titular da situação jurídica discutida. ${ }^{10}$

A autorização do ordenamento jurídico para tal legitimação encontra-se no microssistema do processo coletivo, sendo suas principais fontes o art. $5^{\circ}$ da Lei no 7.347 de 195, a Lei de Ação Civil Pública (LACP) e o art. 82 da Lei nº 8.078 de 1990, o Código de Defesa do Consumidor (CDC). Nelas, o legislador definiu um rol taxativo de entes que teriam legitimidade para propor uma ação coletiva, elencando duas espécies de legitimação coletiva: a legitimação de pessoas jurídicas de direito privado (associações) e a legitimação de entes públicos (Ministério Público, Defensoria Pública e órgãos da Administração Direta e Indireta, etc.). ${ }^{11}$

Como explica Júlio Camargo de Azevedo, em relação às associações, previu-se expressamente a necessidade de preenchimento de dois pressupostos cumulativos para o ajuizamento de ações coletivas: (i) a pré-constituição há pelo menos um ano (requisito este que pode ser desconsiderado pelo juiz ante o manifesto interesse social ou a relevância do bem jurídico protegido, conforme o artigo $5^{\circ}$, inciso $\mathrm{V}$, alínea a e $\$ 4^{\circ}$, LACP e o artigo 82 , inciso IV e $\$ 1^{\circ}$, CDC) e (ii) a compatibilidade da finalidade institucional com a defesa judicial dos direitos objeto da ação civil pública (artigo $5^{\circ}$, inciso $\mathrm{V}$, alínea b, LACP), que vem

5 AZEVEDO, Júlio Camargo de. O microssistema de processo coletivo brasileiro: uma análise feita à luz das tendências codificadoras. Revista Eletrônica de Direito Processual - REDP, Rio de Janeiro, v. VIII, pp. 478-499, 2011, p. 484. Disponível em: <https://www.e-publicacoes.uerj.br/index.php/redp/article/view/20831/15109>. Acesso em 09/09/2020.

6 DIDIER JR., Fredie; ZANETI JR., Hermes. Op. cit., p. 77.

7 VITORELLI, Edilson. Levando os conceitos a sério: processo estrutural, processo coletivo, processo estratégico e suas diferenças. Revista de Processo, São Paulo, v. 284, pp. 333-369, Out. 2018, p. 5. Disponível em: <https://www. academia.edu/40449066/LEVANDO_OS_CONCEITOS_A_S\%C3\%89RIO_PROCESSO_ESTRUTURAL_PROCESSO_ COLETIVO_PROCESSO_ESTRAT\%C3\%89GICO_E_SUAS_DIFEREN\%C3\%87AS>. Acesso em: 09/09/2020.

$8 \quad$ Ibid, p. 5.

$9 \quad$ Fredie Didier Jr. e Hermes Zaneti Jr. apontam, em seu curso, que alguns doutrinadores adotaram a categoria da legitimação autônoma para a condução do processo para classificar a legitimação nos processos coletivos. Como explicam os autores, a justificativa de tal categoria seria a de que o legitimado não vai a juízo na defesa do próprio interesse, portanto não seria legitimado ordinário, nem vai a juízo na defesa de interesse alheio, pois não seria possível identificar o titular do direito discutido. No entanto, Fredie Didider Jr. e Hermes Zaneti Jr. apontam, dentre outros, dois principais equívocos dessa categoria: (i) toda legitimação ad causam é um poder para condução do processo, logo, não haveria nada que justificasse acrescer à designação da categoria o qualificativo de “para a condução do processo" e (ii) a legitimação autônoma seria conceito lógico-jurídico útil à visualização das espécies de legitimação extraordinária, de modo que a legitimação autônoma seria espécie de legitimação extraordinária, na hipótese de o legitimado extraordinário está autorizado a conduzir o processo independentemente da participação do titular do direito litigioso (DIDIER JR., Fredie; ZANETI JR., Hermes. Curso de Direito Processual Civil: processo coletivo. V. 4, 14. ed. Salvador: Ed. Juspodivm, 2020, p. 228-229).

10 DIDIER JR., Fredie; ZANETI JR., Hermes. Op. cit., p. 227.

11 AZEVEDO, Júlio Camargo de. Representatividade adequada: pressuposto processual específico das ações coletivas brasileiras. Revista Eletrônica de Direito Processual - REDP, Rio de Janeiro, v. X, pp. 258-274, 2012, p. 261. Disponível em: <https://www.e-publicacoes.uerj.br/index.php/redp/article/view/20350/14691>. Acesso em: 09/09/2020. 
sendo chamada de "pertinência temática" e representa o vínculo de afinidade temática das associações e o objeto transindividual litigioso. ${ }^{12}$

Sobre a representação, Edilson Vitorelli explica que esta é uma solução pragmática no processo coletivo, mas não uma justificativa para a não participação, sendo esta estrutura representativa o problema que gera a dúvida acerca da compatibilidade do processo coletivo com o devido processo legal. ${ }^{13}$ Isso porque, como aponta o autor, a essência do devido processo legal seria a participação no processo, o que permitiria ao interessado compreender o desenrolar de acontecimentos que resultarão na decisão. Trata-se de elemento que, no entanto, seria ausente no processo coletivo, uma vez que o legitimado coletivo nunca é um integrante da sociedade titular do direito. ${ }^{14}$

Diante desse problema, o referido autor aponta uma nova ideia de participação processual, a partir da sua instrumentalidade, de modo que ela será sempre um meio para alcançar um fim, só sendo valiosa até o limite no qual contribua para esse fim. ${ }^{15}$ Esta instrumentalidade se justificaria pela demonstração de que o processo, enquanto instrumento de realização de direitos, não sofreria prejuízos significativos sem ela. ${ }^{16}$

Esta deve ainda ser encarada no contexto de um sistema que busca estabelecer processos justos para além das partes que figuram em cada uma das demandas ajuizadas, tendo em conta os milhões de litígios que se apresentam ao Poder Judiciário ${ }^{17}$, sendo sua supressão ou restrição condicionada pela avaliação da sobrecarga do sistema jurídico e da possibilidade de obtenção de resultados materiais

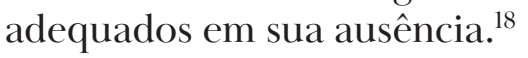

Na linha do exposto, Antonio Gidi explica que no devido processo legal coletivo, os direitos de ser citado, de ser ouvido e de apresentar defesa em juízo são substituídos por um direito de ser citado, ouvido e definido através de um representante. No entanto, o grupo não deveria ser representado em juízo por um representante qualquer, mas por um representante adequado. ${ }^{19}$

Acontece que, como chama atenção Edilson Vitorelli, não há previsão de uma análise de adequação dessa representação. ${ }^{20}$ É neste cenário que se insere a discussão a respeito da possibilidade de controle judicial da legitimação coletiva.

De um lado, há o entendimento de que este seria somente ope legis - ou seja, o legislador teria estabelecido um rol legal de legitimados, firmando uma presunção absoluta de que seriam os representantes adequados. ${ }^{21}$ De outro lado, há o entendimento de que a legitimação poderia passar por

$12 \quad$ Ibid, p. 261.

13 VITORELLI, Edilson. O devido processo legal coletivo: representação, participação e efetividade da tutela jurisdicional. Tese (Doutorado em Direito) - Faculdade de Direito, Universidade Federal do Paraná, Curitiba, 2015, p. 122. Disponível em: <https://acervodigital.ufpr.br/bitstream/handle/1884/40822/R\%20-\%20T\%20-\%20EDILSON\%20 VITORELLI\%20DINIZ\%20LIMA.pdf?sequence=2>. Acesso em: 09/09/2020.

$14 \quad$ Ibid, p. 119.

$15 \quad$ Ibid, p. 214.

16 Ibid, p. 216.

17 Ibid, p. 215.

18 Ibid, p. 217.

19 GIDI, Antonio. A representação adequada nas ações coletivas brasileiras: uma proposta. Revista de Processo, São Paulo, v. 108, n. 61, pp. 61-70, Out-dez, 2002, p. 5. Disponível em: <https://papers.ssrn.com/sol3/papers.cfm?abstract_ $\mathrm{id}=1016416>$. Acesso em: 09/09/2020.

20 VITORELLI, Edilson. O devido processo legal coletivo: representação, participação e efetividade da tutela jurisdicional. Tese (Doutorado em Direito) - Faculdade de Direito, Universidade Federal do Paraná, Curitiba, 2015, p. 123. Disponível em: <https://acervodigital.ufpr.br/bitstream/handle/1884/40822/R\%20-\%20T\%20-\%20EDILSON\%20 VITORELLI\%20DINIZ\%20LIMA.pdf?sequence=2>. Acesso em: 09/09/2020.

21 DIDIER JR., Fredie; ZANETIJR., Hermes. Curso de Direito Processual Civil: processo coletivo. V. 4, 14. ed. Salvador: Ed. Juspodivm, 2020, p. 237. 
um controle ope judicis, no qual o juiz analisaria no caso concreto a representatividade adequada daquele legitimado - ou seja, se reconheceria como relativa a presunção positivada no ordenamento jurídico. ${ }^{22}$

A verificação de tal representatividade adequada ${ }^{23}$ teria como inspiração o modelo de class actions estadunidense, mais especificamente a Regra 23 (a) 4 das Federal Rules of Civil Procedure, segundo a qual, para que uma demanda seja coletivamente admitida, seria necessário que os representantes protejam os interesses da classe de forma justa e adequada. ${ }^{24}$

Tal requisito, no direito estadunidense, é aferido tanto em relação ao representante, quanto ao advogado do grupo, e seria satisfeito a partir dos seguintes elementos: (i) a ausência de conflito de interesses e (ii) a possibilidade de assegurar a vigorosa tutela dos interesses do grupo. ${ }^{25}$

No Brasil, embora alguns defendam a existência de um controle de representatividade adequada apenas opes legis ${ }^{26}$ (ante a inexistência de previsão legal expressa), parte considerável doutrina vem reconhecendo que, além dos critérios estabelecidos em lei, deveria ser possível que o juiz exercesse um controle de representatividade para que o processo atingisse seus escopos da forma mais efetiva possível. ${ }^{27}$

Nessa toada, argumentam Fredie Didier Jr. e Hermes Zaneti Jr. que não seria nem mesmo razoável imaginar que uma entidade, pela simples circunstância de estar autorizada em tese para a condução do processo coletivo, pudesse propor qualquer demanda coletiva, pouco importando suas peculiaridades. ${ }^{28}$ Assim, entende Antonio Gidi que não somente o juiz brasileiro poderia, mas teria o dever de avaliar a adequada representação dos interesses do grupo em juízo. ${ }^{29}$

22 AZEVEDO, Júlio Camargo de. Representatividade adequada: pressuposto processual específico das ações coletivas brasileiras. Revista Eletrônica de Direito Processual - REDP, Rio de Janeiro, v. X, pp. 258-274, 2012, p. 262. Disponível em: <https://www.e-publicacoes.uerj.br/index.php/redp/article/view/20350/14691>. Acesso em: 09/09/2020.

23 João Paulo Lordelo Guimarães Tavares escreve que a adequacy of representation do sistema norte americano seria mais bem traduzida no Brasil como a "legitimação adequada" ou "substituição processual adequada". (TAVARES, João Paulo Lordelo Guimarães. A certificação coletiva: organizando as ações coletivas e o julgamento de casos repetitivos. Salvador: Juspodivm, 2020, p. 142).

24 TAVARES, João Paulo Lordelo Guimarães. Op. cit., p. 142.

25 Ibid, p. 144.

26 Júlio Camargo de Azevedo, ao escrever sobre a representatividade adequada, destaca como defensores da presunção ope legis de representatividade os juristas Nelson e Rosa Nery, Arruda Alvim, Ricardo de Barros Leonel, Pedro da Silva Dinamarco, Gregório Assagra de Almeida, Sérgio Shimura e Elton Venturi. O referido autor destaca ainda os principais argumentos desse entendimento: "a) a prévia identificação hipotética dos entes

legitimados impediria, em tese, o controle judicial; b) a regra já restaria excepcionada no caso das associações, não cabendo aos intérpretes-aplicadores estendê-la a outros legitimados (interpretação restritiva do controle concreto); c) as especificidades normativas do microssistema brasileiro - onde a sentença coletiva jamais serviria a prejudicar os direitos individuais dos integrantes do grupo, somente beneficiá-los (art. 103, $§ \S 1^{\circ}, 2^{\circ}, 3^{\circ}$ do CDC) - implicaria na desnecessidade do controle casuístico; d) a inapropriada atuação do legitimado, que resultasse em uma sentença de improcedência por falta de provas, impediria a formação da coisa julgada material em desfavor da coletividade (adoção, in casu, da coisa julgada "secundum eventum probationis"); e) a intervenção obrigatória do Ministério Público enquanto "custos legis" supriria eventual deficiência apresentada pelos demais representantes processuais” (AZEVEDO, Júlio Camargo de. Representatividade adequada: pressuposto processual específico das ações coletivas brasileiras. Revista Eletrônica de Direito Processual REDP, Rio de Janeiro, v. X, pp. 258-274, 2012, p. 261-262. Disponível em: < https: / / www.e-publicacoes.uerj.br /index.php/ $\mathrm{redp} / \mathrm{article} / \mathrm{view} / 20350 / 14691>$. Acesso em: 09/09/2020).

27 RICHTER, Bianca Mendes Pereira. Representatividade adequada: uma comparação entre o modelo norteamericano da class-action e o modelo brasileiro. Revista Jurídica da Escola Superior do Ministério Público de São Paulo, São Paulo, v. 1, pp. 213-230, 2012, p. 228. Disponível em: <https://es.mpsp.mp.br/revista_esmp/index.php/RJESMPSP/ article/view/25>. Acesso em: 09/09/2020.

28 DIDIER JR., Fredie; ZANETI JR., Hermes. Curso de Direito Processual Civil: processo coletivo. V. 4, 14. ed. Salvador: Ed. Juspodivm, 2020, p. 237.

29 GIDI, Antonio. A representação adequada nas ações coletivas brasileiras: uma proposta. Revista de Processo, São Paulo, v. 108, n. 61, pp. 61-70, Out-dez, 2002, p. 5. Disponível em: <https://papers.ssrn.com/sol3/papers.cfm?abstract_ id=1016416>. Acesso em: 09/09/2020. 
Nesse passo, Edilson Vitorelli critica que o que se convencionou chamar, no Brasil, de controle ope legis da representatividade, na verdade seria a ausência de qualquer controle, uma vez que os critérios para tanto estabelecidos não assegurariam, de qualquer modo, a qualidade da representação. ${ }^{30}$

Ademais, a doutrina também tem apontado que não seria preciso ir tão longe - ou tão "contra a lei" - para se defender o controle judicial da representatividade adequada. Assim explica Eduardo Scarparo que, muito embora nos Estados Unidos a adequação do representante esteja prevista na lei processual (Rule 23), ela trata, acima de tudo, de uma tutela constitucional ao devido processo legal e ao contraditório. ${ }^{31}$ E é nesse sentido que poderia ser entendido, como faz João Paulo Lordelo Guimarães Tavares, que existe no Brasil um fundamento constitucional a esse controle - o devido processo legal -, de modo que a ausência de previsão expressa não seria relevante, em razão da importância que deve ser reconhecida ao devido processo legal coletivo. ${ }^{32}$

Quanto às associações, Flávia Hellmeister Clito Fornaciari ainda destaca que o que se insere no estatuto social de uma sociedade ou associação é obra dos próprios associados, não passando por qualquer fiscalização dos órgãos públicos. ${ }^{33}$

Nesse passo, entende Antonio Gidi que, em que pese o juiz brasileiro não tenha os mesmos poderes que o juiz americano para controlar a adequação do representante em uma ação coletiva, esta não pode ser deixada completamente fora do controle judicial. ${ }^{34}$

O controle da adequação da representatividade poderia ser, então, feito pelo juiz, o que, para Fredie Didier Jr. e Hermes Zaneti Jr., deveria ocorrer a partir de um exame à luz da situação jurídica litigiosa deduzida em juízo, em que se levasse em consideração critérios gerais, preferivelmente previamente estabelecidos ou indicados em rol exemplificativo. ${ }^{35}$

Nessa toada, a doutrina se voltou a tentar estabelecer quais critérios seriam esses, o que levou à consagração da pertinência temática como um dos parâmetros mais apontados (e aplicados) para o exame da representatividade adequada. Portanto, parte-se, neste primeiro momento, para uma análise deste critério.

\section{A Pertinência Temática como Parâmetro de Verificação da Representatividade Adequada}

As associações civis, para ajuizar ações civis públicas ou coletivas, precisam deter representatividade adequada do grupo que pretendam defender em juízo, aferida à vista do preenchimento de dois requisitos: a) pré-constituição há pelo menos um ano nos termos da lei civil - dispensável, quando evidente interesse social; e b) pertinência temática - indispensável e correspondente à finalidade institucional compatível com a defesa judicial do interesse. ${ }^{36}$

30 VITORELLI, Edilson. O devido processo legal coletivo: representação, participação e efetividade da tutela jurisdicional. Tese (Doutorado em Direito) - Faculdade de Direito, Universidade Federal do Paraná, Curitiba, 2015 , p. 404. Disponível em: <https://acervodigital.ufpr.br/bitstream/handle/1884/40822/R\%20-\%20T\%20-\%20EDILSON\%20 VITORELLI\%20DINIZ\%20LIMA.pdf?sequence=2>. Acesso em: 09/09/2020.

31 SCARPARO, Eduardo. Controle da representatividade adequada em processos coletivos no Brasil. Revista de Processo, São Paulo, v. 208, pp. 125-146, Jun., 2012, p. 7. Disponível em: <http: / / www.eduardoscarparo.com.br /2016/11/14/ controle-da-representatividade-adequada-em-processos-coletivos-no-brasil-1/>. Acesso em: 09/09/2020.

32 TAVARES, João Paulo Lordelo Guimarães. A certificação coletiva: organizando as ações coletivas e o julgamento de casos repetitivos. Salvador: Juspodivm, 2020, p. 201-202.

33 FORNACIARI, Flávia Hellmeister Clito. Representatividade adequada nos processos coletivos. Tese (Doutorado em Direito) - Faculdade de Direito, Universidade de São Paulo, São Paulo, 2010, p. 52. Disponível em: <https://www. teses.usp.br/teses/disponiveis/2/2137/tde-24092010-133201/publico/Representatividade_Adequada_nos_Processos_ Coletivos.pdf>. Acesso em: 11/10/20.

34 GIDI, Antonio. A representação adequada nas ações coletivas brasileiras: uma proposta. Revista de Processo, São Paulo, v. 108, n. 61, pp. 61-70, Out-dez, 2002, p. 3. Disponível em: <https://papers.ssrn.com/sol3/papers.cfm?abstract_ $\mathrm{id}=1016416>$. Acesso em: $09 / 09 / 2020$.

35 DIDIER JR., Fredie; ZANETI JR., Hermes. Curso de Direito Processual Civil: processo coletivo. V. 4, 14. ed. Salvador: Ed. Juspodivm, 2020, p. 238.

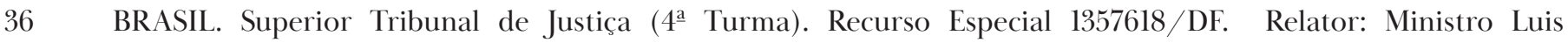
Felipe Salomão, julgado em 26 de setembro de 2017, p. 1. Disponível em: <https://processo.stj.jus.br/processo/ 
O trecho supratranscrito consta de ementa do Recurso Especial no 1357618 , julgado pela Quarta Turma do STJ, em 26/09/2017. A pertinência temática é comumente visualizada na jurisprudência como parâmetro de representatividade adequada. ${ }^{37}$

Como já mencionado, tanto a LACP, quanto o CDC preveem expressamente, em relação às associações, a necessidade de serem preenchidos os requisitos supracitados de lapso temporal mínimo de 1 (um) ano e pertinência subjetiva.

\section{A respeito deste requisito, Eduardo Scarparo esquematiza a evolução do seu conteúdo:}

Inicialmente, a pertinência temática foi compreendida como uma comparação formal entre o objeto do processo e os fins estatutários da associação, nos termos do art. 5. ․ㅡ, V, b, da LACP/1985, com aplicação, portanto, exclusiva às associações. Com o tempo, os tribunais passaram a admitir a representação mediante o reconhecimento de finalidades implícitas no estatuto. Posteriormente, valeu-se do instituto para se exigir um elo substancial entre as finalidades constitucionais do Ministério Público (art. 129) ou dos demais legitimados e o objeto da ação civil pública proposta como as autarquias. Então, na apreciação das ações civis públicas, passou-se a exigir a comprovação da pertinência temática, não como uma simples referência ao estatuto social de uma dada associação, mas como um verdadeiro vínculo entre a atividade de representação da entidade legitimada com o próprio objeto da ação que move. Trata-se de um requisito sem norma expressa, mas cujo feixe principiológico conecta-se frontalmente ao princípio do contraditório. ${ }^{38}$

Como destaca o referido autor, este desdobramento jurisprudencial apontou para a quebra do fundamento estritamente legalista do controle jurisdicional, uma vez que se passou a exigir um efetivo vínculo de afinidade temática entre o legitimado e o objeto litigioso ${ }^{39}$, e não apenas a inclusão genérica no estatuto da associação da "proteção ao meio ambiente, ao consumidor, à ordem econômica, à livre concorrência ou ao patrimônio artístico, estético, histórico, turístico e paisagístico". ${ }^{40}$

Inclusive, é possível visualizar também a verificação jurisprudencial da pertinência temática em relação aos legitimados de direito público, como, por exemplo, o Ministério Público ${ }^{41}$ e a Defensoria

pesquisa $/$ ?src=1.1.3\&aplicacao=processos.ea\&tipoPesquisa=tipoPesquisaGenerica\&num_registro=201202598435 $>$. Acesso em: $09 / 09 / 2020$.

37 Nesse sentido, ver: BRASIL. Superior Tribunal de Justiça (1 $1^{\underline{a}}$ Turma). Recurso Especial 1731299/MG. Relator: Ministro Sérgio Kukina, 16 de maio de 2019, publicado em 23/05/2019; BRASIL. Superior Tribunal de Justiça (1ª Turma). Agravo Interno no Recurso Especial 1350108/DF. Relator: Min. Napoleão Nunes Maia Filho, julgado em 14/08/2018, DJe 23 /08/2018; BRASIL. Tribunal de Justiça do Rio de Janeiro. Apelação Cível 0115411-06.2011.8.19.0001/RJ, Rel. Des. Inês Da Trindade Chaves De Melo, Sexta Câmara Cível, julgado em: 08/11/2017, DJe 18/09/2018; BRASIL. Tribunal de Justiça do Rio de Janeiro. Apelação Cível 0000028-63.2000.8.19.0001, Rel. Des. Antonio Ricardo Binato De Castro, Décima Segunda Câmara Cível, julgado em 24/11/2009, DJe 18/12/2009; BRASIL. TRF-1. AC 2005.34.00.001368-8/DF, Rel. Juiz Federal Rodrigo Navarro De Oliveira, Data de Julgamento: 03/09/2013, 4⿳㇒一a Turma Suplementar, DJe 27/09/2013; BRASIL. TJDF 0022320-26.2010.8.07.0001, Relator: Angelo Canducci Passareli, Data de Julgamento: 11/04/2012, 5 Turma Cível, DJe 13/04/2012; BRASIL. TRF-1. AC 0036205-72.2005.4.01.3400, Relatora: Maria Do Carmo Cardoso, Data de Julgamento: 21/08/2017, 8 ${ }^{\text {a }}$ Turma, Data de Publicação: 29 /09/2017 e-DJF1; BRASIL. TRF-3. AC: 10365 SP 0010365-54.2005.4.03.6100, Relator: Desembargador Federal Mairan Maia, Data de Julgamento: 06/09/2012, 6 $6^{\mathrm{a}}$ Turma; BRASIL. TRF-2. AC: 002188613.2005.4.02.5101/RJ, Relator: Poul Erik Dyrlund, Data de Julgamento: 01/02/2011, 8 ${ }^{\underline{a}}$ Turma Especializada, Data de Publicação: 15/02/2011; BRASIL. TRF-2. AC: 425453 RJ 2008.51.01.012113-1, Relator: Desembargador Federal Guilherme Calmon Nogueira Da Gama, Data de Julgamento: 17/06/2009, 6 ${ }^{\mathbf{a}}$ Turma Especializada, Data de Publicação: DJU - Data: 30/06/2009, p. 91-92.

38 SCARPARO, Eduardo. Controle da representatividade adequada em processos coletivos no Brasil. Revista de Processo, São Paulo, v. 208, pp. 125-146, Jun., 2012, p. 6. Disponível em: <http: / / www.eduardoscarparo.com.br / 2016/11/14/ controle-da-representatividade-adequada-em-processos-coletivos-no-brasil-1/>. Acesso em: 09/09/2020.

39 DIDIER JR., Fredie; ZANETIJR., Hermes. Curso de Direito Processual Civil: processo coletivo. V. 4, 14. ed. Salvador: Ed. Juspodivm, 2020, p. 238.

40 SCARPARO, Eduardo. Controle da representatividade adequada em processos coletivos no Brasil. Revista de Processo, São Paulo, v. 208, pp. 125-146, Jun., 2012, p. 7. Disponível em: <http: / / www.eduardoscarparo.com.br / 2016/11/14/ controle-da-representatividade-adequada-em-processos-coletivos-no-brasil-1/>. Acesso em: 09/09/2020.

41 Como exemplifica Eduardo Scarparo: "o STJ negou a possibilidade de o Ministério Público, por meio da Ação Civil Pública, tutelar a nulidade de cláusulas abusivas em contratos de locação residencial (AgRg no REsp 442.822/RS, rel. Min Gilson Dipp, DJ 13.10.2003, benefícios de aposentadoria a portadores de deficiência (REsp 502.744/SC, rel. Min. José Arnaldo 
Pública $^{42}$. No entanto, há de se destacar que a Terceira Turma do STJ, ao julgar o Recurso Especial 1059586, proferiu decisão, em 15/05/2018, no sentido de que:

[...] em relação ao Ministério Público e aos entes políticos, que tem como finalidades institucionais a proteção de valores fundamentais, como a defesa coletiva dos consumidores, não se exige pertinência temática e representatividade adequada. ${ }^{43}$

Nesse passo, vem se relacionando tal requisito a uma forma de controle jurisdicional da adequação da representatividade. É sobre isso que se refere Susana Henrique da Costa, ao afirmar que a exigência jurisprudencial da pertinência temática no caso concreto, mesmo nos casos em que a lei não menciona nada a respeito, levou a doutrina brasileira a rever o entendimento de que no sistema vigente não seria permitido o controle judicial da representatividade adequada do legitimado à propositura da ação civil pública. ${ }^{44}$

O problema dessa relação, como aponta Bianca Mendes Pereira Richter, é que, apesar de se tratar de uma forma de controle, não seria sinônimo de representatividade adequada, uma vez que esta abrangeria, além do vínculo, vários outros critérios. ${ }^{45}$ No mesmo sentido escrevem Fredie Didier

da Fonseca, DJ 25.04.2005), ou de dissolução de sociedade anônima em benefício dos acionistas (REsp 36.098/SP, rel. Min. Ari Pargendler, DJ 03.04.2000). Ademais, o Conselho Superior do Ministério Público editou a Súmula 7 com o seguinte teor: ‘O Ministério Público está legitimado à defesa de interesses individuais homogêneos que tenham expressão para a coletividade, como: (a) os que digam respeito à saúde ou a segurança das pessoas ou ao acesso das crianças e adolescentes à educação; (b) aqueles em que haja extraordinária dispersão dos lesados; (c) quando convenha à coletividade o zelo pelo funcionamento de um sistema econômico, social ou jurídico" (SCARPARO, Eduardo. Controle da representatividade adequada em processos coletivos no Brasil. Revista de Processo, São Paulo, v. 208, pp. 125-146, Jun., 2012, p. 12. Disponível em: <http://www. eduardoscarparo.com.br /2016/11/14/controle-da-representatividade-adequada-em-processos-coletivos-no-brasil-1/>. Acesso em: 09/09/2020).

42 A Quarta Turma do STJ, em 15/05/2014, proferiu decisão em que analisou a pertinência subjetiva da Defensoria Pública para ajuizar ações coletivas em defesa de interesses difusos, pois entendeu que "no tocante à legitimidade ativa da Defensoria Pública para o ajuizamento de ação civil pública, não bastou um mero exame taxativo da lei, havendo sim um controle judicial sobre a representatividade adequada da legitimação coletiva. Com efeito, para chegar à conclusão da existência ou não de pertinência temática entre o direito material em litígio e as atribuições constitucionais da parte autora acabou-se adentrando no terreno do mérito". Consignou-se que a "Defensoria Pública tem pertinência subjetiva para ajuizar ações coletivas em defesa de interesses difusos, coletivos ou individuais homogêneos, sendo que no tocante aos difusos, sua legitimidade será ampla (basta que possa beneficiar grupo de pessoas necessitadas), haja vista que o direito tutelado é pertencente a pessoas indeterminadas. No entanto, em se tratando de interesses coletivos em sentido estrito ou individuais homogêneos, diante de grupos determinados de lesados, a legitimação deverá ser restrita às pessoas notadamente necessitadas". (BRASIL. Superior Tribunal de Justiça (4- Turma). Recurso Especial 1192577 / RS. Processual civil. Ação civil pública. Embargos infringentes. Legitimidade da defensoria pública para a propositura de ação civil pública. Limitador constitucional. Defesa dos necessitados. Plano de saúde. Reajuste. Grupo de consumidores que não é apto a conferir legitimidade àquela instituição. Relator: Ministro Luis Felipe Salomão, 15 de maio de 2014, p. 1-2. Disponível em: <https:// processo.stj.jus.br / processo / pesquisa $/$ ?src=1.1.3\&aplicacao=processos.ea\&tipoPesquisa=tipoPesquisaGenerica\&num_ registro=201000805877>. Acesso em: 09/09/2020).

43 BRASIL. Superior Tribunal de Justiça (3 $3^{-}$Turma). Recurso Especial 1509586/SC. Processual civil. Recurso especial. Ação civil pública. Direito do consumidor. Bancário. Cobrança de tarifa de renovação de cadastro. Interesses individuais homogêneos.Legitimidadeativa.Município.Pertinênciatemática.Representaçãoadequada. Relatora:MinistraNancyAndrighi, 15 de maio de 2018. Disponível em: <https://processo.stj.jus.br / processo/pesquisa $/$ ?src=1.1.3\&aplicacao=processos. ea\&tipoPesquisa=tipoPesquisaGenerica\&num_registro=201500194906>. Acesso em: 09/09/2020.

44 COSTA, Susana Henriques da. O controle judicial da representatividade adequada: uma análise dos sistemas norteamericano e brasileiro. In: SALLES, Carlos Alberto de. (Coord.). As grandes transformações do processo civil brasileiro: homenagem ao professor Kazuo Watanabe. São Paulo: Quartier Latin, 2009, p. 972. APUD RICHTER, Bianca Mendes Pereira. Representatividade adequada: uma comparação entre o modelo norte-americano da class-action e o modelo brasileiro. Revista Jurídica da Escola Superior do Ministério Público de São Paulo, v. 1, pp. 213-230, 2012, p. 225. Disponível em: <https://es.mpsp.mp.br/revista_esmp/index.php/RJESMPSP/article/view/25>. Acesso em: 09/09/2020.

45 RICHTER, Bianca Mendes Pereira. Representatividade adequada: uma comparação entre o modelo norteamericano da class-action e o modelo brasileiro. Revista Jurídica da Escola Superior do Ministério Público de São Paulo, v. 1, pp. 213-230, 2012, p. 224-225. Disponível em: <https://es.mpsp.mp.br / revista_esmp/index.php/RJESMPSP/article/ view $/ 25>$. Acesso em: $09 / 09 / 2020$. 
Jr. e Hermes Zaneti Jr. quanto ao fato deste ser um, dentre vários, para a averiguação da adequação do legitimado coletivo. ${ }^{46}$

Antes de adentrar na análise de quais seriam esses outros critérios, e ainda como uma forma de permitir a melhor visualização do referido problema, cabe inseri-lo no contexto do modelo representativo brasileiro.

\section{Análise do Modelo Representativo Brasileiro e o Problema do Controle da Representatividade Adequada}

Ao analisar o modelo representativo brasileiro, Edilson Vitorelli concluiu que, apesar de teoricamente misto, o sistema representativo do processo coletivo brasileiro é eminentemente público. ${ }^{47}$ Ou seja, a maior parte das ações coletivas são propostas por entes públicos e não, por exemplo, por associações. $^{48}$

Nesse sentido, em relatório analítico propositivo realizado pelo Departamento de Pesquisas Judiciárias do Conselho Nacional de Justiça (DPJ/CNJ), em 2018, se observou que o Ministério Público era a parte predominante em todos os tribunais, ao passo que as entidades da sociedade civil teriam baixa representatividade comparadas a ele. ${ }^{49}$

Edilson Vitorelli aponta como uma vantagem da prevalência de entidades públicas no polo ativo das ações coletivas, a eliminação do potencial de conflito financeiro entre o representante e os representados, que seria um problema central nas ações coletivas norte-americanas. ${ }^{50}$

Por outro lado, aduz que o problema de um sistema representativo público seria a redução dos mecanismos de alinhamento de interesses entre os atores processuais, uma vez que a parte que ajuíza a ação nada tem a ganhar ou a perder com ela, não se podendo assim garantir que sua atuação será tão vigorosa quanto a de um advogado economicamente motivado. Ademais, os servidores que integram os órgãos legitimados não teriam obrigação legal, nem estímulo racional de verificar os interesses da classe representada. ${ }^{51}$

No entanto, apesar desse cenário de prevalência de um sistema representativo público, o debate quanto à verificação da representatividade adequada acabou por ficar mais restrito às associações, de modo que os critérios deste controle estariam mais voltados para entidades que, na prática, possuem

46 DIDIER JR., Fredie; ZANETI JR., Hermes. Curso de Direito Processual Civil: processo coletivo. V. 4, 14. ed. Salvador: Ed. Juspodivm, 2020, p. 238.

47 VITORELLI, Edilson. O devido processo legal coletivo: representação, participação e efetividade da tutela jurisdicional. Tese (Doutorado em Direito) - Faculdade de Direito, Universidade Federal do Paraná, Curitiba, 2015 , p. 394. Disponível em: <https://acervodigital.ufpr.br/bitstream/handle/1884/40822/R\%20-\%20T\%20-\%20EDILSON\%20 VITORELLI\%20DINIZ\%20LIMA.pdf?sequence=2>. Acesso em: 09/09/2020.

48 Adriane Reis de Araújo, Cássio Luís Casagrande e Ricardo José Macedo de Britto Pereira apontam ter existido uma vontade do constituinte de que fosse dada certa primazia à atividade do Ministério Público na defesa de interesses coletivos da sociedade, o que poderia ser percebido pelo fato de que a ação civil pública não foi situada no capítulo dos direitos e garantias fundamentais, como ocorre com outras ações constitucionais. (ARAÚJO, Adriane Reis de; CASAGRANDE, Cássio Luís; PEREIRA, Ricardo José Macedo de Britto. Ações civis públicas no TST: atuação do Ministério Público do Trabalho e dos sindicatos em perspectiva comparada. Caderno CEDES, Escola Superior do Ministério Público da União (Iuperj), Rio de Janeiro, n. 6, dezembro, 2006, p. 12. Disponível em: <http:/ / www.cis.puc-rio.br / cis /cedes /PDF / cadernos / cadernos\%20 6\%20-\%20acaocivilmp.pdf>. Acesso em: 09/12/20).

49 CONSElHO NACIONAL DE JUSTIÇA. Ações coletivas no Brasil: temas, atores e desafios da tutela coletiva. Relatório analítico propositivo sobre ações coletivas no Brasil. Série Justiça Pesquisa, Departamento de Pesquisas Judiciárias do Conselho Nacional de Justiça (DPJ/CNJ), 2018, p. 65-66. Disponível em: <https://www.cnj.jus.br/wp-content/ uploads /2011/02/799b01d7a3f27f85b334448b8554c914.pdf>. Acesso em: 09/12/20.

50 VITORELLI, Edilson. O devido processo legal coletivo: representação, participação e efetividade da tutela jurisdicional. Tese (Doutorado em Direito) - Faculdade de Direito, Universidade Federal do Paraná, Curitiba, 2015 , p. 397. Disponível em: <https://acervodigital.ufpr.br/bitstream/handle/1884/40822/R\%20-\%20T\%20-\%20EDILSON\%20 VITORELLI\%20DINIZ\%20LIMA.pdf?sequence=2>. Acesso em: 09/09/2020.

51 Ibid, p. 399-400. 
atuação menor, enquanto se reservaria uma presunção de adequação maior aos entes públicos, que, por sua vez, são mais atuantes.

Esse cenário é criticado pela doutrina, na medida em que os legitimados públicos, independentemente de outras condições, estão, via de regra, mais distantes do contato cotidiano com os titulares dos direitos violados, o que reduz sua capacidade de representar os interesses dos ausentes. ${ }^{52}$ Para autores como Antonio Gidi, Fredie Didier Jr, Hermes Zaneti Jr., até o Ministério Público poderia ser um representante inadequado em alguns casos específicos. ${ }^{53} 54$

Como já demonstrado, a pertinência temática vem sendo exigida também de outros legitimados, ainda que sem previsão legal nesse sentido. Para Edilson Vitorelli, tal exigência se fez por meio de interpretação ao previsto para as associações. O referido autor critica, no entanto, que tal critério pouco significaria ${ }^{55}$, uma vez que, por exemplo, o Ministério Público possui uma finalidade institucional prevista na CRFB/88 muito ampla.

Ademais, para Edilson Vitoreli, a ausência de representação adequada pode decorrer de incúria, despreparo ou má-fé, mas também pode derivar apenas da identificação inadequada ou incompleta dos interesses dos titulares do direito. ${ }^{56}$ Nesse ponto, é crítico o fato de a lei não ter imposto aos legitimados um procedimento para verificação dos interessados da classe, nem ter exigido que, uma vez identificados, o representante agisse de acordo com eles. ${ }^{57}$

Desse modo, a pertinência temática acaba se revelando com um critério que, na prática, pode ser insuficiente para a devida verificação da adequação da representatividade, principalmente se considerando que o Ministério Público é o legitimado mais atuante.

Parece possível ainda ser feita outra crítica, no sentido de que este parâmetro também não parece significar de fato um controle em concreto pelo juiz. Isso porque, ainda que seu conteúdo tenha sido ampliado, sua exigência em relação aos outros legitimados, que não as associações, se faz por interpretação de critério fixado previamente pelo legislador.

Nesse ponto, pertinente destacar que o sistema de verificação ope legis é aquele feito pelo legislador, a partir da indicação na lei de quais os requisitos necessários a fim de legitimar determinado corpo intermediário a atuar em nome de uma coletividade. Já o ope judis consiste no controle típico do juiz, que, ante as especificidades do caso concreto, avalia se o legitimado que se apresenta tem as condições para cumprir a representação adequadamente. ${ }^{58}$

Ademais, imperioso também trazer a explicação Flávia Hellmeister Clito Fornaciari sobre a natureza objetiva e subjetiva dos requisitos da adequação. Sobre os objetivos, cabe transcrever as palavras da autora:

[...] ocorre quando a própria lei os especifica, anotando quais as características que deve ter o representante para tanto. No sistema brasileiro atualmente em vigor, entende-se existir previsão da representatividade adequada, no que toca à legitimação ativa do grupo, ainda que não expressa pela lei nesse sentido. A doutrina extrai esse

52 VITORELLI, Edilson. O devido processo legal coletivo: representação, participação e efetividade da tutela jurisdicional. Tese (Doutorado em Direito) - Faculdade de Direito, Universidade Federal do Paraná, Curitiba, 2015 , p. 405. Disponível em: <https://acervodigital.ufpr.br/bitstream/handle/1884/40822/R\%20-\%20T\%20-\%20EDILSON\%20 VITORELLI\%20DINIZ\%20LIMA.pdf?sequence=2>. Acesso em: 09/09/2020.

53 GIDI, Antonio. A representação adequada nas ações coletivas brasileiras: uma proposta. Revista de Processo, São Paulo, v. 108, n. 61, pp. 61-70, p. 3. Out-dez, 2002. Disponível em: <https://papers.ssrn.com/sol3/papers.cfm?abstract_ id=1016416 $>$. Acesso em: 09/09/2020.

54 DIDIER JR., Fredie; ZANETIJR., Hermes. Curso de Direito Processual Civil: processo coletivo. V. 4, 14. ed. Salvador: Ed. Juspodivm, 2020, p. 238.

55 VITORELLI, Edilson. Op. cit., p. 405.

$56 \quad$ Ibid, p. 409.

57 Ibid, p. 405.

58 SCARPARO, Eduardo. Controle da representatividade adequada em processos coletivos no Brasil. Revista de Processo, São Paulo, v. 208, pp. 125-146, Jun., 2012, p. 4-5. Disponível em: <http://www.eduardoscarparo.com. br $/ 2016 / 11 / 14 /$ controle-da-representatividade-adequada-em-processos-coletivos-no-brasil-1/>. Acesso em: $09 / 09 / 2020$. 
instituto da especificação, pela lei brasileira, de que as sociedades e associações, para figurarem como autoras da ação coletiva, devem ter tempo mínimo de constituição e de seus estatutos sociais deve constar, como finalidade, a proteção dos direitos envolvidos. Ou seja, nesse caso específico, deve o juiz analisar, de acordo com os estritos termos da lei, se existe pertinência temática entre o que consta no estatuto social das associações e o que ela pretende tutela em juízo, configurando exigência ope legis da adequada representação, pois a própria lei já estabelece critérios suficientes para que a adequação seja afirmada. ${ }^{59}$

Por sua vez, os critérios subjetivos são definidos, como esclarece a referida autora, a partir da credibilidade, capacidade, prestígio, experiência do legitimado, histórico na proteção judicial ou extrajudicial dos interesses do grupo, conduta em outros processos, coincidência entre interesses, tempo de instituição da associação e representatividade do indivíduo frente ao grupo. Trata-se de circunstâncias que devem ser analisadas no caso concreto pelo magistrado. ${ }^{60}$

Portanto, ainda que a lei estabeleça a necessidade de verificação de pertinência temática apenas às associações, a exigência desta em relação aos demais legitimados ocorreu por interpretação do controle ope legis da representatividade. Acontece que existem outros parâmetros mais relevantes que de fato constituem critérios subjetivos e só podem (e devem) ser percebidos a partir de um controle pelo juiz diante efetivamente do caso concreto. Passa-se à análise dos referidos.

\section{Por uma Verificação mais Adequada da Representatividade Adequada}

Flávia Hellmeister Clito Fornaciari, ao estudar a definição para representatividade adequada, conclui que a mais acertada é aquela que representa uma qualidade apresentada pelo representante que atuará em nome do grupo na defesa de interesses de ordem coletiva, qualidade essa identificada como a possibilidade da defesa eficiente e tenaz dos interesses envolvidos, seja no âmbito social, administrativo ou judicial. ${ }^{61}$

Nesse passo, a autora propõe que o estudo deste instituto deve ser feito de forma isolada, fora do contexto da legitimidade. Do mesmo modo, Edilson Vitorelli sustenta a adoção de uma perspectiva panprocessualista, ou seja, que compreendesse o alcance das garantias processuais para além da relação endoprocessual existente entre o autor e o réu ${ }^{62}$ no processo coletivo. ${ }^{63}$

É necessário, portanto, levar em conta, no estudo do processo coletivo, as relações existentes entre a classe substituída e o autor coletivo, bem como entre os membros da classe, ainda que essas relações sejam externas ao processo. Para Edilson Vitorelli, elas constituem - e devem constituir elementos condicionantes ao processo coletivo. ${ }^{64}$

Trata-se de conclusão relacionada ao próprio princípio do devido processo legal coletivo, uma vez que este imporia que se construísse um processo adequado às peculiaridades do caso concreto, na

59 FORNACIARI, Flávia Hellmeister Clito. Representatividade adequada nos processos coletivos. Tese (Doutorado em Direito) - Faculdade de Direito, Universidade de São Paulo, São Paulo, 2010, p. 52-53. Disponível em: <https://www. teses.usp.br/teses/disponiveis/2/2137/tde-24092010-133201/publico/Representatividade_Adequada_nos_Processos_ Coletivos.pdf>. Acesso em: $11 / 10 / 20$.

$60 \quad$ Ibid, p. 52-53.

$61 \quad$ Ibid, p. 50.

62 Isso porque, para o autor, da perspectiva endoprocessual, não haveria grandes diferenças entre o devido processo legal individual e o devido processo legal coletivo, uma vez que, no âmbito da relação entre autor coletivo e réu, a aplicação das garantias do processo se desenvolveria sem grandes alterações em relação a um processo individual (VITORELLI, Edilson. O devido processo legal coletivo: representação, participação e efetividade da tutela jurisdicional. Tese (Doutorado em Direito) - Faculdade de Direito, Universidade Federal do Paraná, Curitiba, 2015, p. 170-171. Disponível em: <https:// acervodigital.ufpr.br/bitstream/handle/1884/40822/R\%20-\%20T\%20-\%20EDILSON\%20VITORELLI\%20DINIZ\%20 LIMA.pdf?sequence=2>. Acesso em: 09/09/2020).

63 VITORELLI, Edilson. Op. cit., p. 171.

$64 \quad$ Ibid, p. 172. 
medida em que, como sintetizam Fredie Didier Jr. e Hermes Zaneti Jr., um procedimento adequado apenas no plano legislativo não concretizaria suficientemente o princípio da adequação. ${ }^{65}$

Nessa toada, Edilson Vitorelli chamou atenção para a necessidade de os direitos transindividuais serem cindidos em três categorias, que levariam em consideração a sociedade que os titulariza, sob a perspectiva da lesão ou ameaça de lesão que é afirmada no processo e que sustenta a pretensão da tutela. ${ }^{66}$

Esta categoria possui dois pressupostos. O primeiro é de que a titularidade dos direitos transindividuais só pode ser definida quando se está tratando de sua violação, ou seja, no contexto de um litígio coletivo. ${ }^{67}$ Já o segundo envolve dois conceitos: (i) o da complexidade, como elemento que deriva das múltiplas possibilidades de tutela de um direito, não sendo todas necessariamente equivalentes em termos fáticos, mas igualmente possíveis juridicamente e (ii) o da conflituosidade, como elemento que deve ser avaliado a partir da uniformidade das posições dos integrantes da sociedade em relação ao litígio. ${ }^{6}$

Assim, em síntese, quanto mais variados forem os aspectos da lesão e as possibilidades de tutela, maior será o grau de complexidade do litígio, ao passo que, quanto mais variado for o modo como os integrantes de uma sociedade são atingidos por uma lesão, maior será a conflituosidade. ${ }^{69}$

Enfim, com base nestes pressupostos, Edilson Vitorelli propõe uma divisão em três categorias de litígios coletivos. A primeira seria a dos litígios de difusão global, que consistiria na situação em que a lesão não atinge diretamente os interesses de qualquer pessoa.$^{70}$ Já a segunda é a de litígios de difusão local, sendo aquela em que a lesão atinge, de modo específico e grave, uma comunidade (grupo de reduzidas dimensões e fortes laços de afinidade social, emocional e territorial, traduzidos em um alto grau de consenso interno ${ }^{71}$. Por fim, a terceira refere-se aos litígios de difusão irradiada, que envolvem as situações em que o litígio decorrente da lesão afeta diretamente os interesses de diversas pessoas ou segmentos sociais, mas essas pessoas não compõem uma comunidade, não têm a mesma perspectiva social e não serão atingidas, da mesma forma e com a mesma intensidade, pelo resultado do litígio. ${ }^{72}$

Assim, sintetizam Fredie Didier Jr. e Hermes Zaneti Jr. duas conclusões relevantes obtidas a partir da contribuição de Edilson Vitorelli: (i) em relação aos litígios irradiados, é necessário que se adote o conceito de zonas de interesse, deixando-se de lado a dualidade autor e réu, ante a elevada conflituosidade interna e (ii) em relação a todos os litígios, é preciso que a adequação da representatividade seja verificada levando em consideração a complexidade do litígio, não só no momento inicial, mas durante toda a condução do processo.

Tal controle, para Fredie Didier Jr. e Hermes ZanetiJr., seria realizado em duas fases: primeiramente se verificaria se há autorização legal para que determinado ente possa substituir os titulares coletivos do direito afirmado, e a seguir, o órgão julgador faria um controle in concreto da adequação da legitimidade para aferir, sempre motivadamente, se estão presentes os elementos que asseguram a representatividade adequada dos direitos em discussão. ${ }^{73}$

65 DIDIER JR., Fredie; ZANETI JR., Hermes. Curso de Direito Processual Civil: processo coletivo. V. 4, 14. ed. Salvador: Ed. Juspodivm, 2020, p. 111.

66 VITORELLI, Edilson. Op. cit., p. 74.

67 Ibid, p. 74.

$68 \quad$ Ibid, p. 76.

69 VITORELLI, Edilson. O devido processo legal coletivo: representação, participação e efetividade da tutela jurisdicional. Tese (Doutorado em Direito) - Faculdade de Direito, Universidade Federal do Paraná, Curitiba, 2015 , p. 76. Disponível em: <https://acervodigital.ufpr.br/bitstream/handle/1884/40822/R\%20-\%20T\%20-\%20EDILSON\%20 VITORELLI\%20DINIZ\%20LIMA.pdf?sequence=2>. Acesso em: 09/09/2020.

$70 \quad$ Ibid, p. 78.

$71 \quad$ Ibid, p. 83.

72 Ibid, p. 88.

73 DIDIER JR., Fredie; ZANETIJR., Hermes. Curso de Direito Processual Civil: processo coletivo. V. 4, 14. ed. Salvador: Ed. Juspodivm, 2020, p. 238. 
João Paulo Lordelo Guimarães Tavares, ao propor que a decisão de saneamento e organização nos processos coletivo deve servir de uma espécie de "certificação brasileira", estabelece que a análise da representatividade adequada nos processos coletivos deveria fazer parte do conteúdo dessa decisão. ${ }^{74}$

Nessa toada, o referido autor propõe um roteiro de controle de legitimação adequada nas ações coletivas brasileira, estabelecendo, como primeiro pressuposto, que existe uma relação direta entre a definição dos grupos e a verificação da adequação do seu representante.

Assim, o juiz deveria inicialmente atentar ao tipo de conflito em tratativa, a evidenciar o nível de complexidade e de conflituosidade do caso. Tratando-se: (i) de litígios de natureza global, o controle seria algo mais simples, na medida em que um único legitimado seria suficiente para a defesa da coletividade; (ii) de litígios de difusão local, se exigiria a atenção quanto à existência de excessiva litigiosidade interna ao grupo, o que poderia resultar em conflitos de interesse entre o legitimado coletivo e os subgrupos existente - afastando, portanto, a adequação do representante e (iii) de litígios de difusão irradiada, o controle da representatividade envolveria a análise da necessidade de mais de um legitimado coletivo, ou, a depender do caso, de um legitimado único, mas cujas atribuições possuam maior amplitude, de modo a estabelecer um vínculo entre os variados grupos de interesse. ${ }^{75}$

Após a identificação do conflito, João Paulo Lordelo propõe que o juiz passe ao exame da pertinência temática, analisando a existência de nexo entre o perfil institucional do legitimado que propõe a ação e o objeto do litígio coletivo. Constatada a pertinência, deve-se analisar a existência de eventuais conflitos de interesses entre o legitimado coletivo e o grupo, inclusive quanto aos advogados e às causas de impedimento e suspeição dos membros do Ministério Público.

Por fim, o autor ainda aponta como um importante filtro o exame do histórico de atuação do legitimado coletivo, o que envolve o grau de representatividade perante o grupo, a sua credibilidade e conduta em outros processos.

Em relação ao Ministério Público, Flávia Hellmeister Clito Fornaciari escreve que, em que pese a representatividade adequada não seja analisada a partir da credibilidade ou capacidade do ente ministerial, ela deve atender aos critérios de coincidência de interesses da sociedade, ou seja, da representatividade do Ministério Público na questão específica, em relação à sociedade.

Ademais, a referida autora ainda aponta que as mesmas restrições passíveis de serem feitas a qualquer outro legitimado podem recair sobre o representante do Ministério Público, uma vez que seria possível, no caso concreto, a pretensão de projeção social individual do representante da instituição ou mesmo dela própria, em detrimento da efetiva tutela dos direitos coletivos ou indisponíveis. ${ }^{76}$ Tal situação, portanto, indicaria a necessidade de controle da representatividade desse órgão.

\section{Conclusão}

Como consequência da adoção de um modelo representativo de processo coletivo, tem-se, no Brasil, que a coletividade é substituída por um legitimado extraordinário, salvo pontuais exceções. ${ }^{77}$

A referida substituição provoca especial preocupação com a observância do devido processo legal, vez que esse representa, dentre outros direitos, o de participação, ao passo que, em uma ação coletiva, os interesses dos titulares do direito material não estão sendo por eles diretamente tutelados ou representados, mas sim pelo legitimado extraordinário.

74 TAVARES, João Paulo Lordelo Guimarães. A certificação coletiva: organizando as ações coletivas e o julgamento de casos repetitivos. Salvador: Juspodivm, 2020, p. 200.

$75 \quad$ Ibid, p. 205-206.

76 FORNACIARI, Flávia Hellmeister Clito. Representatividade adequada nos processos coletivos. Tese (Doutorado em Direito) - Faculdade de Direito, Universidade de São Paulo, São Paulo, 2010, p. 81-81. Disponível em: <https://www. teses.usp.br/teses/disponiveis/2/2137/tde-24092010-133201/publico/Representatividade_Adequada_nos_Processos_ Coletivos.pdf>. Acesso em: $11 / 10 / 20$.

77 Cita-se, como exemplo, a legitimidade ordinária do cidadão autor de Ação Popular. 
Nesse passo, um devido processo legal coletivo demandaria a análise da qualidade - ou adequação - dessa substituição, à luz das peculiaridades do caso concreto. Tal análise se refletiria em um controle feito pelo juiz, que poderia acabar por afastar até mesmo as presunções legais de legitimação.

Seria esse o controle ope judicis da representatividade adequada, defendido por relevante parte da doutrina que enxerga o devido processo legal como fundamento para sua verificação no caso concreto.

À vista disso, a doutrina se esforça para definir critérios necessários ao juiz no momento da realização desse controle. Um ponto merecedor de atenção nesse rumo é o fato de que a maioria das ações coletivas é conduzida por legitimados públicos, em especial o Ministério Público, o que faz com que a preocupação com a representatividade adequada deva ir além de critérios que esse legitimado, por sua ampla finalidade institucional, já atenderia.

Um exemplo crítico é a pertinência temática, critério muito apontado, mas que não só se trata, em última análise, de parâmetro pré-definido pelo legislador (ainda que seu conteúdo tenha passado por modificações), como também acaba por não significar um controle para o Ministério Público, legitimado que mais propõe ações coletivas no país.

Assim, à luz de todas as diretrizes doutrinárias destacadas, é possível afirmar que um efetivo controle pelo juiz da representatividade adequada envolve, principalmente, o exame do tipo de complexidade do litígio em questão, da conflituosidade entre os integrantes do grupo representado (atentando à eventual existência de zonas de interesses), a condução antes e durante o processo e o grau de representatividade no caso concreto.

Bem realizado, o controle da representatividade adequada permitiria se aproximar satisfatoriamente de uma conciliação entre os fins pragmáticos e as consequências da adoção de um modelo representativo e o devido processo legal coletivo, visto que o cuidado para com a adequação da representatividade nada mais é do que uma preocupação com a observância dessa garantia constitucional no contexto e realidade do processo coletivo.

\section{Referências}

ARAÚJO, Adriane Reis de; CASAGRANDE, Cássio Luís; PEREIRA, Ricardo José Macedo de Britto. Ações civis públicas no TST: atuação do Ministério Público do Trabalho e dos sindicatos em perspectiva comparada. Caderno CEDES, Escola Superior do Ministério Público da União (Iuperj), Rio de Janeiro, n. 6, dezembro, 2006. Disponível em: <http://www.cis.puc-rio.br/cis/ cedes/PDF/cadernos/cadernos\%206\%20-\%20acaocivilmp.pdf>. Acesso em: 09/12/20.

AZEVEDO, Júlio Camargo de. O microssistema de processo coletivo brasileiro: uma análise feita à luz das tendências codificadoras. Revista Eletrônica de Direito Processual - REDP, Rio de Janeiro, v. VIII, pp. 478-499, 2011. Disponível em: <https://www.e-publicacoes.uerj.br/index. $\mathrm{php} / \mathrm{redp} /$ article/view/20831/15109>. Acesso em: 09/09/2020.

AZEVEDO, Júlio Camargo de. Representatividade adequada: pressuposto processual específico das ações coletivas brasileiras. Revista Eletrônica de Direito Processual - REDP, Rio de Janeiro, v. X, pp. 258-274, 2012. Disponível em: <https://www.e-publicacoes.uerj.br/index.php/redp/ article/view/20350/14691>. Acesso em: 09/09/2020

BRASIL. Superior Tribunal de Justiça (1 $1^{\circ}$ Turma). Recurso Especial 510150/MA. Administrativo e processual. Improbidade administrativa. Ação civil pública. Relator: Ministro Luiz Fux, 17 de fevereiro de 2004. Disponível em: <https://processo.stj.jus.br/processo/ pesquisa $/$ src $=1.1 .3 \&$ aplicacao $=$ processos.ea\&tipoPesquisa $=$ tipoPesquisaGenerica\&num_ registro $=200300078957>$. Acesso em: 09/09/2020).

BRASIL. Superior Tribunal de Justiça (4ª Turma). Recurso Especial 1357618/DF. Recurso especial. Ação civil pública. Produtos alimentícios. Obrigação de informar a presença ou não de glúten. Legitimidade ativa de associação. Requisito temporal. Constituição há, pelo menos, um 
ano. Flexibilização. Interesse social e relevância do bem jurídico tutelado. Direito humano à alimentação adequada. Defesa dos consumidores. Promoção da segurança alimentar e nutricional. Relator: Ministro Luis Felipe Salomão, julgado em 26 de setembro de 2017. Disponível em: $<$ https://processo.stj.jus.br/processo/pesquisa/?src=1.1.3\&aplicacao=processos. ea\&tipoPesquisa=tipoPesquisaGenerica\&num_registro=201202598435>. Acesso em: $09 / 09 / 2020$.

CABRAL, Antonio do Passo. Despolarização do processo e "zonas de interesse": sobre a migração entre polos da demanda. Revista da SJRJ, Rio de Janeiro, n. 26, pp. 19-55, 2009. Disponível em: <https://www.jfrj.jus.br/sites/default/files/revista-sjrj/arquivo/25-76-1-pb.pdf>. Acesso em: $09 / 09 / 2020$.

CONSELHO NACIONAL DE JUSTIÇA. Ações coletivas no Brasil: temas, atores e desafios da tutela coletiva. Relatório analítico propositivo sobre ações coletivas no Brasil. Série Justiça Pesquisa, Departamento de Pesquisas Judiciárias do Conselho Nacional de Justiça (DPJ/CNJ), 2018. Disponível em: <https://www.cnj.jus.br/wp-content/ uploads/2011/02/799b01d7a3f27f85b334448b8554c914.pdf>. Acesso em: 09/12/20.

DIDIER JR., Fredie; ZANETI JR., Hermes. Curso de Direito Processual Civil: processo coletivo. V. 4, 14. ed. Salvador: Ed. Juspodivm, 2020, 672p.

FORNACIARI, Flávia Hellmeister Clito. Representatividade adequada nos processos coletivos. Tese (Doutorado em Direito) - Faculdade de Direito, Universidade de São Paulo, São Paulo, 2010. Disponível em: <https://www.teses.usp.br/teses/disponiveis/2/2137/tde-24092010-133201/ publico/Representatividade_Adequada_nos_Processos_Coletivos.pdf $>$. Acesso em: 11/10/20.

GIDI, Antonio. A representação adequada nas ações coletivas brasileiras: uma proposta. Revista de Processo, São Paulo, v. 108, n. 61, pp. 61-70, Out-dez, 2002. Disponível em: <https://papers.ssrn. com/sol3/papers.cfm?abstract_id=1016416>. Acesso em: 09/09/2020.

RICHTER, Bianca Mendes Pereira. Representatividade adequada: uma comparação entre o modelo norte-americano da class-action e o modelo brasileiro. Revista Jurídica da Escola Superior do Ministério Público de São Paulo, São Paulo, v. 1, pp. 213-230, 2012. Disponível em: $<$ https://es.mpsp.mp.br/revista_esmp/index.php/RJESMPSP/article/view/25>. Acesso em: $09 / 09 / 2020$.

SCARPARO, Eduardo. Controle da representatividade adequada em processos coletivos no Brasil. Revista de Processo, São Paulo, v. 208, pp. 125-146, Jun., 2012. Disponível em: <http://www. eduardoscarparo.com.br/2016/11/14/controle-da-representatividade-adequada-em-processoscoletivos-no-brasil-1/>. Acesso em: 09/09/2020.

TAVARES, João Paulo Lordelo Guimarães. A certificação coletiva: organizando as ações coletivas e o julgamento de casos repetitivos. Salvador: Juspodivm, 2020, 288p.

VITORELLI, Edilson. Levando os conceitos a sério: processo estrutural, processo coletivo, processo estratégico e suas diferenças. Revista de Processo, São Paulo, v. 284, pp. 333369, Out. 2018. Disponível em: <https://www.academia.edu/40449066/LEVANDO_OS_ CONCEITOS_A_S\%C3\%89RIO_PROCESSO_ESTRUTURAL_PROCESSO_COLETIVO_ PROCESSO_ESTRAT\%C3\%89GICO_E_SUAS_DIFEREN\%C3\%87AS>. Acesso em: $09 / 09 / 2020$.

VITORELLI, Edilson. O devido processo legal coletivo: representação, participação e efetividade da tutela jurisdicional. Tese (Doutorado em Direito) - Faculdade de Direito, Universidade Federal do Paraná, Curitiba, 2015. Disponível em: <https://acervodigital.ufpr.br/bitstream/ handle/1884/40822/R\%20-\%20T\%20-\%20EDILSON\%20VITORELLI\%20DINIZ\%20LIMA. pdf?sequence $=2>$. Acesso em: 09/09/2020. 